\title{
Comparison of Upper Limb Translocated Femoral Vein and Prosthetic Arteriovenous Bridge Grafts
}

\author{
Muhammad Asad Moosa ${ }^{1}$, Fareed A. Shaikh ${ }^{1}$, Madeeha Ali ${ }^{2}$, Abdus Salam ${ }^{3}$, Ziad Sophie ${ }^{1}$, Nadeem \\ Siddiqui ${ }^{1}$ \\ 1. Surgery, Aga Khan University Hospital, Karachi, PAK 2. General Surgery, Aga Khan University Hospital, Karachi, PAK \\ 3. Surgery, The Aga Khan University, Karachi, PAK
}

Corresponding author: Muhammad Asad Moosa,dr.amoosa@gmail.com

\begin{abstract}
\section{Introduction}

Native veins are an ideal option for dialysis in a patient with chronic kidney disease (CKD) as compared to a prosthetic graft. Femoral vein (FV) translocation to the upper arm is also an alternative to a prosthetic graft as reported in the literature when all options of using the native veins of the arms are exhausted. Thus, we aimed to compare the patency of the upper limb translocated FV arteriovenous fistula (AVF) with a prosthetic arteriovenous bridge graft (AVBG).
\end{abstract}

\section{Methods}

It is a retrospective cohort study that was conducted in the Department of Vascular Surgery, Aga Khan University Hospital. It included adult patients who underwent either upper arm translocation of FV or prosthetic AVBG using the consecutive purposive sampling technique. There were a total of 10 patients who underwent FV translocation AVF and 20 patients who had AVBG in the upper arms.

\section{Results}

A total of 30 patients were included in the study. Of these 30 patients, 10 underwent FV translocation AVF and the remaining 20 had AVBG. There was a significant difference in the mean operating time of the two surgeries. The mean operating time in FV translocation was $223( \pm 41.5)$ minutes and in those with AVBG, the mean operating time was $100( \pm 26.5)(\mathrm{p}=<0.001)$. There was no significant difference in the total length of hospital stay in both procedures performed. The primary patency rate for $\mathrm{FV}$ translocation was $90 \%$ and $95 \%$ in AVBG ( $\mathrm{p}=1.00$ ). Ten percent of FV translocation had a primary failure rate compared with that of AVBG, which was $5 \%(p=1.00)$. The mean follow-up period was 61 weeks in the FV translocation group and 64 weeks in the AVG group.

\section{Conclusion}

Received 11/13/2019

Review began 11/15/2019 Review ended 11/20/2019 Published 11/22/2019

\section{() Copyright 2019}

Moosa et al. This is an open access article distributed under the terms of the Creative Commons Attribution License CC-BY 3.0., which permits unrestricted use, distribution, and reproduction in any medium, provided the original author and source are credited.
There was no significant difference in both groups in terms of patency, length of hospital stay, and fewer complications were observed in the FV translocation group as compared with the AVBG group.

Categories: Cardiac/Thoracic/Vascular Surgery, General Surgery, Nephrology

Keywords: dialysis access, femoral vein, avbg, vein translocation, arteriovenous fistula

\section{Introduction}

The goal of long-term vascular access is rapid and repeated exchange of blood to the body's circulation with fewer complications [1]. Establishing a native vein arteriovenous fistula is always not possible, especially in patients with old age and diabetes [2-3]. In such circumstances, vascular access grafts are used [4]. However, prosthetics are associated with lower survival, higher complication rates, and limited graft patency due to repeated puncturing [5-6]. The alternate is the femoral vein (FV), which has the added benefit of a larger diameter $(6-10 \mathrm{~mm})$ and had been used in situations where upper limb veins were exhausted or in repeated prosthetic graft failures [7-11]. However, FV translocation is also associated with added complications, including steal syndrome, wound complications, and venous leg swellings [6]. To the best of our knowledge, there is no published literature comparing FV translocation to the upper limb with an arteriovenous bridge graft (AVBG) in the upper limb. Therefore, we conducted a retrospective comparative study with the primary objective to compare the patency of FV translocation AVF and AVBG in the upper limb. Our secondary objectives were to compare the overall wound-related complications, duration of surgery, and length of hospital stay.

\section{Materials And Methods}

This is a retrospective cohort study that was conducted at the Department of Surgery, Aga Khan University Hospital, Karachi, Pakistan. Approval from the university's ethical review committee was obtained (4581- 
Sur-ERC-16). The duration of this study was from January 1, 2015, to February 28, 2018. FV translocation was performed in patients with exhausted veins and who were young, non-obese, and able to withstand two different wounds and prolonged surgery. As compared to this, AVBG was on priority for patients who were elderly, frail, and with multiple comorbidities. So during the study period, adult patients who underwent either upper arm translocation femoral vein grafts (Group A) or prosthetic arteriovenous bridge grafts (AVBG) (Group B) for permanent hemodialysis access were included.

In the AVBG group, a 6-millimeter polytetrafluoroethylene (PTFE) graft was used in every procedure and the graft was tunneled subcutaneously in the arm after two separate incisions in the axilla and lower arm. The graft was anastomosed in an end-to-side anastomosis fashion with the brachial artery and the axillary vein. In the FV translocation group, a longitudinal incision in the thigh, extending from the groin to the lower thigh, was given. The femoral vein was dissected along its course up till the knee and harvested. Two separate incisions were given in the arm (one in the axilla and one in the lower arm). The harvested vein was tunneled subcutaneously and anastomosed in an end-to-side fashion with the brachial artery and the axillary vein.

One-year follow-up was gained through a phone call interview, and relevant questions regarding fistula patency and other complications were asked. If a follow-up in the clinic was required, the patients were asked to visit the clinic free of cost. Patients with incomplete follow-up (less than one year), patients with incomplete medical records, and patients who expired or were not available at the time of the phone interview were excluded. The sampling technique was consecutive purposive (patients were recruited who fulfilled the criteria for inclusion until the required sample was achieved). During the specified study period, 10 patients underwent FV translocation AVF. To compare this, 20 patients who underwent AVBG during the same time period and of the same age range were enrolled in the study. Data were collected by means of a questionnaire that was filled for the sample population by the data analyst who was a member of the team. All the data were collected retrospectively from the patients' medical records.

Data regarding the patients' demographics, type of procedure, complications, including wound dehiscence, hematoma, surgical site infection, duration of surgery, and length of hospital stay, were collected from the patient's medical records. Data were analyzed using Statistical Package for Social Sciences (SPSS) version 21.0 (IBM Corp., Armonk, NY) [12]. Mean \pm standard deviation was computed for numerical variables. T-test, chi-square test, and correlation analysis were used for variable comparison within the two groups.

Statistically, the level of significance was taken at $\mathrm{p}<0.05$.

\section{Results}

A total of 10 patients underwent FV translocation and 20 patients were selected from the AVBG group. The median age for patients receiving FV translocation was 47.5 (IQR 19-63) years and for those with AVBG, it was 55 (IQR 22-68) years. The major comorbidities in these patients were diabetes (60\% in FV vs $75 \%$ in AVBG) and hypertension (70\% in FV and 95\% in AVBG) (Table 1).

\begin{tabular}{|l|l|l|}
\hline & FV (n=10) & AVBG (n=20) \\
\hline Median Age (IQR) & $47.5(19-63)$ & $55(22-68)$ \\
\hline Diabetes Mellitus (DM) & $6(60 \%)$ & $14(75 \%)$ \\
\hline Hypertension (HTN) & $7(70 \%)$ & $1( \pm 5 \%)$ \\
\hline $\begin{array}{l}\text { Previous Access Surgeries (Mean +/- SD) } \\
\text { Operating Time in Mins (Mean +/- SD) }\end{array}$ & $2( \pm 1.3)$ & $100( \pm 26.5)$ \\
\hline $\begin{array}{l}\text { Length of Stay (Mean +/- SD) } \\
\text { Mean Follow-up (Weeks) }\end{array}$ & $223( \pm 41.5)$ & $2( \pm 0.394)$ \\
\hline
\end{tabular}

\section{TABLE 1: Details of patients of the two groups (FV v/s AVBG)}

FV: femoral vein; AVBG: arteriovenous bridge graft

There was a significant difference in the mean operating time of the two surgeries. The mean operating time for an FV translocation was $223( \pm 41.5)$ minutes and for those with an AVBG, the mean operating time was $100( \pm 26.5)(p<0.001)$. There was no significant difference in the total length of hospital stay in both groups of patients. Half of the FV translocations $(n=5)$ were matured and used before six weeks (Table 2). However, $80 \%$ of the AVBG $(n=16)$ were used and matured before six weeks. 


\section{Cureus}

\begin{tabular}{|c|c|c|c|}
\hline Time of First Use & FV (n=10) & AVBG $(n=20)$ & $p$-value \\
\hline Less than 6 weeks & $5(50 \%)$ & $16(80 \%)$ & 0.115 \\
\hline At 6 weeks & $5(50 \%)$ & $4(20 \%)$ & 0.115 \\
\hline
\end{tabular}

\section{TABLE 2: Maturation time}

AVBG: arteriovenous bridge graft

In terms of patency, the primary patency rate for FV translocation was $90 \%$, and it was $95 \%$ in AVBG $(\mathrm{p}=1.00)$. Ten percent of FV translocation had a primary failure rate as compared with that of AVBG, which was $5 \%(\mathrm{p}=1.00)($ Table 3$)$.

\begin{tabular}{|c|c|c|c|}
\hline & FV (n=10) & AVBG $(n=20)$ & p-value \\
\hline Patency & 9 (90\%) & 19 (95\%) & 1.000 \\
\hline Primary Failure & 1 (10\%) & $1(5 \%)$ & 1.000 \\
\hline
\end{tabular}

\section{TABLE 3: Patency of the two groups (FV v/s AVBG)}

FV: femoral vein; AVBG: arteriovenous bridge graft

Thigh wound infection was observed in only one patient with FV translocation. An ischemic complication, including steal syndrome, was seen in three patients with AVBG and not seen in the FV translocation group (Table 4). One patient with FV translocation required an additional procedure to assist patency but the number increased in patients with AVBG, i.e. a total of three patients. Graft infection and central venous stenosis were seen in one patient with AVBG (Table 4).

\begin{tabular}{|c|c|c|}
\hline & $F V(n=10)$ & AVBG $(n=20)$ \\
\hline Wound Infection & 1 & - \\
\hline Postop Hematoma & - & - \\
\hline Hand Ischemia/Steal & - & 3 \\
\hline Intervention to Assist Patency & 1 & 3 \\
\hline Graft Infection & - & 1 \\
\hline Central Vein Stenosis & - & 1 \\
\hline
\end{tabular}

TABLE 4: Complications in both groups

FV: femoral vein; AVBG: arteriovenous bridge graft

\section{Discussion}

Femoral vein translocation was first described in a case report in 2000 by Huber et al. [13] and then later in an outcome study in 2004 [7]. After that, very few published studies have discussed the pros and cons of this technique. FV translocations are more invasive and a time-consuming procedure when compared to standard AVBG and careful patient selection is very important. It also gives the advantage of being a native vein fistula with less infectious complications with comparable patency. It is advisable that it should be offered to a younger population who can withstand a long surgical procedure without excessive morbidity. The primary aim of this study was to perform a comparison analysis of the two techniques in a dialysis vascular access creation. This comparison will later help in selecting appropriate dialysis access for a patient. Another reason for this comparison is to cut down on the cost of the prosthetic graft used in AVBG if possible, which is an added treatment cost. Maintaining the treatment cost for a dialysis patient in our 
The maturity time in our study of FV translocations was five weeks, which, in comparison to a case series from Huber et al., showed a maturity time of seven weeks [7]. Another study showed similar results for fistula maturation, which was four weeks [13]. The primary patency rate of FV translocation in our study was $90 \%$ in the FV, which is comparable to the parent study done by Huber et al. who had a patency rate of $96 \%$ in FV translocation [14]. Overall, the translocation of FV was associated with fewer complications in our study. But, Huber et al. reported the breakdown of the vein harvest wound as a known complication of an FV translocation [7]. However, the complication rate from our center was less, and only $10 \%$ of our patients had a wound complication. Another study from Rueda, et al. showed comparable results in length of stay, but slightly higher complication rates, which were 45\% [10]. Wound complications were higher in their study because they did not use a drain in their initial patients, this was then decreased to $13 \%$ when initiating the use of drains [10]. Drains were often used in our FV translocation patients with thigh wounds.

Interestingly, ischemic complications were higher in the AVBG group when compared to the FV translocation group, which is an important finding in our study. Higher ischemic complications may be explained by the presence of peripheral arterial disease in AVBG patients. Ischemic complications in both techniques have been reported previously by Matsuura, et al. [15] who showed 3\% of hand ischemia in AVBG and $2 \%$ in the femoral vein graft. However, this can be avoided by getting preoperative imaging of the arteries, particularly in elderly patients, which was not performed. This assessment is not a routine in our setting due to financial constraints.

Selecting an appropriate dialysis access option in patients who have all the upper limb veins exhausted is a critical step. The results of this study favor FV translocation in younger patients with a longer life expectancy on dialysis and having a low risk of postoperative morbidities. The major limitations of this study is the low number of patients in the FV translocation group, unequal sample size between the two groups for comparison, and due to its retrospective nature, an inability to get complete information because of the inadequate documentation on follow-ups. We plan to further modify the results of this study by collecting larger amounts of data and comparing them in a prospective manner and with at least two years of follow-up post-intervention. The major strengths that this study provides centers on the first comparative study to see the difference in one-year patency between the two techniques.

\section{Conclusions}

There was no difference in terms of patency between the two procedures. However, the surgical time necessary to perform an FV translocation procedure was higher than for AVBG. No difference was noted in the length of hospital stay, and postoperative complications were higher in the AVBG group. Upper limb translocation of the FV can be an alternative option in patients with exhausted upper limb veins, as the patency rate for an upper limb translocated FV is exceptional and comparable to AVBG. However, knowing the magnitude of morbidities, the patient population for such a procedure should be selected after complete and careful assessment.

\section{Additional Information \\ Disclosures}

Human subjects: Consent was obtained by all participants in this study. Aga Khan University Ethical Review Committee issued approval (4581-Sur-ERC-16). Animal subjects: All authors have confirmed that this study did not involve animal subjects or tissue. Conflicts of interest: In compliance with the ICMJE uniform disclosure form, all authors declare the following: Payment/services info: All authors have declared that no financial support was received from any organization for the submitted work. Financial relationships: All authors have declared that they have no financial relationships at present or within the previous three years with any organizations that might have an interest in the submitted work. Other relationships: All authors have declared that there are no other relationships or activities that could appear to have influenced the submitted work.

\section{References}

1. Afshar R, Sanavi S, Afshin-Majd S, Davati A: Outcomes of two different polytetrafluoroethylene graft sizes in patients undergoing maintenance hemodialysis. Indian J Nephrol. 2009, 19:149-152.

2. Staramos DN, Lazarides MK, Tzilalis VD, Ekonomou CS, Simopoulos CE, Dayantas JN: Patency of autologous and prosthetic arteriovenous fistulas in elderly patients. Eur J Surg. 2000, 166:777-781.

3. Avorn J, Winkelmayer WC, Bohn RL, Levin R, Glynn RJ, Levy E, Owen W Jr: Delayed nephrologist referral and inadequate vascular access in patients with advanced chronic kidney failure. J Clin Epidemiol. 2002, 55:711-716. 10.1016/s0895-4356(02)00415-8

4. Morosetti M, Cipriani S, Dominijanni S, Pisani G, Frattarelli D, Bruno F: Basilic vein transposition versus biosynthetic prosthesis as vascular access for hemodialysis. J Vasc Surg. 2011, 54:1713-1719. 10.1016/j.jvs.2011.06.030

5. Young EW, Dykstra DM, Goodkin DA, Mapes DL, Wolfe RA, Held PJ: Hemodialysis vascular access preferences and outcomes in the Dialysis Outcomes and Practice Patterns Study (DOPPS). Kidney Int. 2002, 


\section{Cureus}

61:2266-2271. 10.1046/j.1523-1755.2002.00387.x

6. Van Tricht I, De Wachter D, Tordoir J, Vanhercke D, Verdonck P: Experimental analysis of the hemodynamics in punctured vascular access grafts. ASAIO J. 2005, 51:352-359.

10.1097/01.mat.0000169126.91756.1d

7. Huber TS, Hirneise CM, Lee WA, Flynn TC, Seeger JM: Outcome after autogenous brachial-axillary translocated superficial femoropopliteal vein hemodialysis access. J Vasc Surg. 2004, 40:311-318. 10.1016/j.jvs.2004.04.018

8. Scollay JM, Skipworth RJ, Severn A, Nagy J, Howd A, Griffiths GD: Vascular access using the superficial femoral vein. J Vasc Access. 2010, 11:312-315. 10.5301/jva.2010.2748

9. Kapala A, Szczesny W, Stankiewicz W, Hryncewicz W: Vascular access for chronic dialysis using the superficial femoral vein. J Vasc Access. 2003, 4:150-153. 10.1177/112972980300400404

10. Rueda CA, Nehler MR, Kimball TA, Dimond KR, Whitehill TA, Peyton BD: Arteriovenous fistula construction using femoral vein in the thigh and upper extremity: single-center experience. Ann Vasc Surg. 2008, 22:814. 10.1016/j.avsg.2008.08.002

11. Sadaghianloo N, Jean-Baptiste E, Mousnier A, Declemy S, Hassen-Khodja R: Arm composite autogenous vascular access using the great saphenous vein and the femoral vein: results from a single-centre study. Eur J Vasc Endovasc Surg. 2013, 45:183-188. 10.1016/j.ejvs.2012.11.030

12. IBM SPSS Statistics for Windows, Version 21.0 . (2012). https://www.ibm.com/analytics/spss-statisticssoftware?cm_mmc=Search_Google-_-Hybrid+Cloud_Data+Science-_-WW_IN-_-ibm....

13. Huber TS, Ozaki CK, Flynn TC, Ross EA, Seeger JM: Use of superficial femoral vein for hemodialysis arteriovenous access. J Vasc Surg. 2000, 31:1038-1041. 10.1067/mva.2000.104587

14. Huber TS, Carter JW, Carter RL, Seeger JM: Patency of autogenous and polytetrafluoroethylene upper extremity arteriovenous hemodialysis accesses: a systematic review. J Vasc Surg. 2003, 38:1005-1011. 10.1016/s0741-5214(03)00426-9

15. Matsuura JH, Johansen KH, Rosenthal D, Clark MD, Clarke KA, Kirby LB: Cryopreserved femoral vein grafts for difficult hemodialysis access. Ann Vasc Surg. 2000, 14:50-55. 10.1007/s100169910009 